\title{
Role of terlipressin in preventing Acute Kidney Injury in refractory severe septic shock
}

\author{
Pla, G.; Lloret, B.; Vives, M.; Policarpo, G.; Hernando, B.; Hernández, C. \\ Hospital Universitari Dr. Josep Trueta. Girona. Catalunya.
}

\section{BACKGROUND:}

Terlipressine could prevent acute kidney injury (AKI) in refracory severe septic shock (SS) by decreasing the use of noradrenaline and by decreasing the vasoconstriction of the afferent glomerular arteriole is suggested by our case report.

\section{CASE REPORT:}

\section{A 70 years-old women}

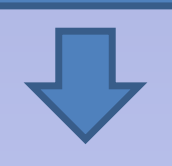

Ileostomy because of colonic cancer surgery in 2015, presented faecal peritonitis and severe SS secondary to suture failure of ileostomy closure and required emergent surgery in the immediate postoperative period.

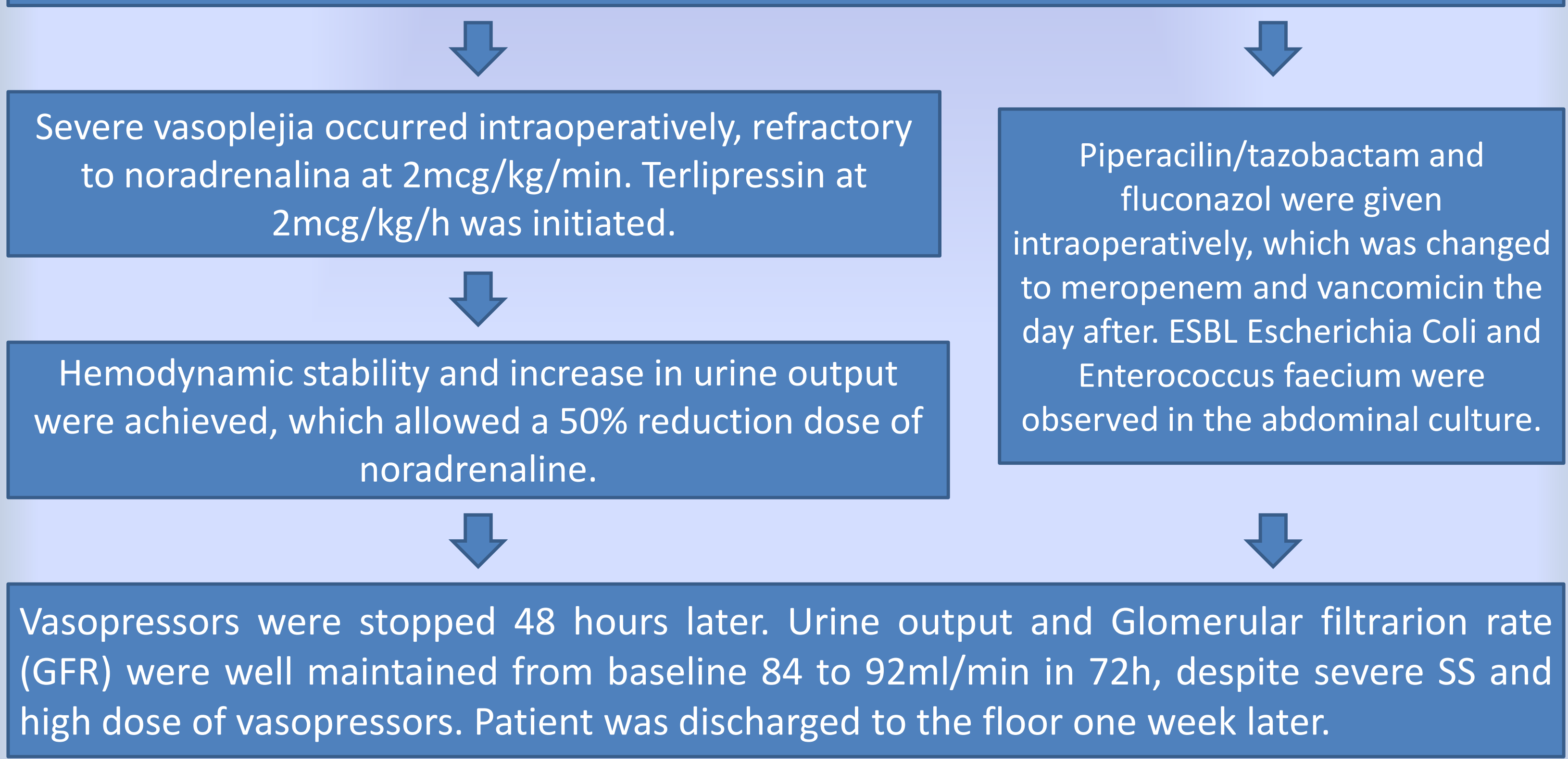

\section{DISCUSSION:}

- In severe septic shock the benefit of using vasopressin is unclear.

- A case of severe abdominal refractory SS, who benefit from using terlipressin infusion, leading to a $50 \%$ reduction of noradrenalina.

- This fact could be explained by the predominant vasoconstrictor effect of terlipressin on efferent glomerular arteriole and therefore an improvement in GFR.

\section{CONCLUSION:}

The use of terlipressin in severe refractory SS is suggested, as may have a role in preventing AKI associated with Severe Septic Shock. 